HUMANAS E SOCIAIS

V.9 • N.2 • 2021 • Fluxo Contínuo

ISSN Digital: 2316-3801

ISSN Impresso: 2316-3348

DOI: $10.17564 / 2316-3801.2021 v 9 n 2 p 468-483$
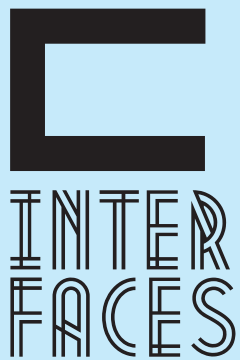

CIENTÍFICAS

\section{O CENTENÁRIO DA MORTE DE GEORGE WILLIAM BUTLER: A TRAJETÓRIA DO MISSIONÁRIO PROTESTANTE E MÉDICO NORTE-AMERICANO NO BRASIL}

THE CENTENARY OF THE DEATH OF GEORGE WILLIAM BUTLER:

THE TRAJECTORY OF THE PROTESTANT MISSIONARY AND

AMERICAN DOCTOR IN BRAZIL

EL CENTENARIO DE LA MUERTE DE GEORGE WILLIAM BUTLER: LA TRAYECTORIA DEL MISIONERO PROTESTANTE Y MÉDICO ESTADOUNIDENSE EN BRASIL

\section{RESUMO}

Esta investigação versa sobre as relações religiosas, políticas e sociais construídas pelo missionário protestante George Butler, especificamente em Pernambuco, entre o final do século XIX e início do século XX. Sua trajetória se assemelha a de tantos outros norte-americanos que se deslocaram para várias partes do mundo com o objetivo de propagar o protestantismo, mas ao mesmo tempo se distancia pela sua atuação como médico e por suas ligações pessoais e políticas. Dessa forma, ao narrar sobre parte da vida de Butler, quando atuou na cidade de Canhotinho, Agreste de Pernambuco, objetivamos problematizar como o protestantismo foi sendo introduzido no Brasil, convertendo inúmeras pessoas e seus familiares, também como a presença desses missionários e tais conversões provocaram diversas reações, ainda estranheza de setores da sociedade e da Igreja Católica Romana.

\section{PALAVRAS-CHAVE}

Protestantismo. George Butler. Canhotinho. Conversão 


\section{ABSTRACT}

This investigation deals with the religious, political and social relations built by the Protestant missionary George Butler, specifically in Pernambuco, between the end of the 19th century and the beginning of the 20th century. Thus, when narrating about part of Butler's life, when he worked in the city of Canhotinho, Agreste de Pernambuco, we aimed to problematize how Protestantism was being introduced in Brazil, converting countless people and their families, and how the presence of these missionaries and such conversions provoked various reactions and strangeness of sectors of society and the Roman Catholic Church.

\section{KEYWORDS}

Protestantism. George Butler. Canhotinho. Conversion

\section{RESUMEN}

Esta investigación trata sobre las relaciones religiosas, políticas y sociales construidas por el misionero protestante George Butler, específicamente en Pernambuco, entre el final del siglo 19 y el comienzo del siglo 20. Así, al narrar parte de la vida de Butler, cuando trabajaba en la ciudad de Canhotinho, Agreste de Pernambuco, nos propusimos problematizar cómo se estaba introduciendo el protestantismo en Brasil, convirtiendo a innumerables personas y sus familias, y cómo la presencia de estos misioneros y tales conversiones provocó diversas reacciones y extrañeza de sectores de la sociedad y la Iglesia Católica Romana.

\section{PALABRAS CLAVE}

Protestantismo. George Butler. Canhotinho. Conversión 


\section{TEMPLO DA MEMÓRIA}

A presença de missionários protestantes norte-americanos sempre foi algo presente na minha infância e juventude. Nasci e residi, por aproximadamente 18 anos, na área rural de Águas Belas, cidade distante cerca de 300 quilômetros da capital Recife, localizada numa região de transição entre o Agreste e o Sertão de Pernambuco. Ali passou a atuar, desde o final da década de 1970, um casal de missionários protestantes provenientes do sul dos Estados Unidos, ligados à Missão Novas Tribos do Brasil².

O objetivo do senhor Edward e da senhora Margareth Happer era atuar junto ao povo indígena Fulni-ô e outros setores da sociedade que permitissem um bom diálogo. A interação/aproximação com a minha família aconteceu quase de imediato, muito em função da nossa vinculação ao protestantismo, pois éramos integrantes da Igreja Presbiteriana do Brasil em Águas Belas. Filiação religiosa que, aliás, remonta ao final do século XIX e início do XX quando membros da família Vilela foram alvo das ações de pregadores protestantes norte-americanos nas cidades de Garanhuns e Canhotinho.

Em nossa residência logo foi iniciado um trabalho de evangelização. Durante vários anos, na década de 1980 e início da década de 1990, aqueles missionários estiveram à frente dessa atividade religiosa ao mesmo tempo em que se aproximavam da comunidade indígena Fulni-ô. Dessa forma, a presença destes na minha infância e juventude foi constante e vista com bastante naturalidade, havendo inclusive contribuído para a formação escolar minha e de meus irmãos/irmãs ao permitir que pudéssemos em várias ocasiões pernoitar em sua residência após as aulas noturnas na sede do município.

Mesmo após o término de suas atuações na Missão Novas Tribos do Brasil permaneceram residindo em Águas Belas até o início de 2018, quando problemas de saúde os fizeram retornar aos Estados Unidos. A construção de vínculos e a inserção na sociedade foi uma realidade que atingiu inúmeros missionários, voluntários do Corpos da $\mathrm{Paz}^{3}$ e agentes do governo dos Estados Unidos da América (EUA) que, nas décadas de 1960 e 1970, foram designados para atuar com mais intensidade no Brasil e em toda a América Latina4.

Assim, na segunda metade do século XX era bastante comum identificar norte-americanos residindo e/ou circulando em cidades de Pernambuco e de outros estados, principalmente do Nordeste brasileiro, região que, segundo o governo dos Estados Unidos, possuía um enorme potencial revolucionário. Tal visão justificava-se devido à miséria em que vivia a maioria da população e, devido à existência de organizações de esquerda, como as Ligas Camponesas lideradas pelo advogado e deputado federal Francisco Julião e que defendiam a reforma agrária na lei ou na marra ${ }^{5}$.

2 A Missão Novas Tribos do Brasil tem sede na cidade de Anápolis/GO e atua na catequese/evangelização dos povos indígenas desde a sua formação por norte-americanos em meados do século XX. Ver outras informações no site: http://www.novastribosdobrasil.org.br. Acesso em: 18 out. 2017.

3 Era uma agência independente criada em 1961 durante o governo de John Kennedy para ajudar os países em desenvolvimento, prestando serviços considerados essenciais e promovendo a interação, a amizade e paz entre americanos e povos de outras culturas (AZEVEDO, 2007).

4 Sobre a presença de norte-americanos no Brasil (BLACK, 1978).

5 Em relação ao medo do comunismo em Pernambuco e no Nordeste (PORFÍRIO, 2009. 
Ainda sobre essas lembranças da minha infância e adolescência, que durante muito tempo apresentaram-se a mim como naturais, ressalto hoje minha necessidade e motivação de, como historiador, problematizá-las, ao discutir/investigar a atuação desses missionários no Brasil. Entretanto é preciso dizer que tais investigações precisam pautar os sucessos e insucessos desses agentes, as amizades construídas, as perseguições e ameaças sofridas provenientes de setores da Igreja Católica Apostólica Romana, ou seja, pensar suas relações/inserções na sociedade naquele momento. Mas é necessário avançar ainda mais e investigar a existência de um discurso religioso/político/ético fundante capaz de impulsionar, desde meados do século XIX, milhares de jovens norte-americanos a migrarem para o Brasil e toda a América Latina.

\section{A PRESENÇA DOS MISSIONÁRIOS PRESBITERIANOS ESTADUNIDENSES NO BRASIL: UM MODELO DE CIVILLZAÇ̃̃o}

O influente jurista e parlamentar Aureliano Tavares Bastos, representando importantes setores políticos no Segundo Reinado, defendia que o Brasil deveria se aproximar dos Estados Unidos não só nos aspectos políticos e econômicos, ele defendia também que se deveria incentivar internamente um influxo do caráter civilizador norte-americano. Além do que, apresentava duas maneiras que permitiriam ao Brasil maior contato com o espírito civilizador da nação do Norte. Uma dessas maneiras era incentivando um processo migratório para o Brasil de contingentes de norte-americanos que após a Guerra de Secessão e a derrota dos Confederados do Sul estavam procurando na América do Sul um novo lar.

Com este intuito e, tendo o apoio de inúmeros políticos de tendências liberais, ajudou a estruturar a Sociedade Internacional de Imigrantes em 1866, cujo objetivo era realizar campanhas para estimular a imigração em massa de sulistas dos EUA para o Brasil. Defendia, também, como eficiente maneira de ampliar o contato com a próspera civilização dos EUA, uma permissão que o Império deveria conceder aos missionários protestantes norte-americanos que àquela altura chegavam ao Brasil para difundir sua doutrina. Acreditava Tavares Bastos que a religião protestante pudesse produzir na sociedade brasileira as mesmas transformações civilizatórias que entendia haverem acontecido nos EUA (PEREIRA, 2007).

Essa demanda civilizatória pode explicar, em parte, o não cumprimento da Constituição de 1824 no que tange à temática religiosa. A esse respeito uma série de critérios e proibições era preconizada: que a religião oficial do Brasil era o Catolicismo Romano; que, entre outras questões, era proibida a realização de ações evangelizadoras com o objetivo de fazer prosélitos; que pregassem em língua portuguesa; que os locais de culto fossem identificados como tais externamente.

Professor do Seminário Presbiteriano do Norte, no Recife, o teólogo José Roberto de Souza afirmou que de fato a Constituição de 1824 não era observada em sua totalidade, havendo o próprio missionário presbiteriano Ashbel Green Simonton procurado aprender a língua portuguesa quando chegou ao Brasil em 1859 - mais precisamente ao Rio de Janeiro, então capital do país - o que lhe possibilitou pregar e/ou evangelizar os brasileiros na língua local sem qualquer interferência das autoridades nacionais (SOUZA, 2011, p. 137-155). 
A presença destes missionários presbiterianos no Brasil, constituindo o que foi denominado de protestantismo de missão ${ }^{6}$, proveniente dos Estados Unidos, seguiu algumas especificidades. É importante ressaltar que desde a primeira metade do século XIX questões como o escravismo no território norte-americano vinham provocando fortes tensões na Igreja Presbiteriana de seu país. E com os conflitos gerados pela Guerra de Secessão (1861-1865) - conhecida também como a Guerra Civil - houve uma ruptura definitiva, surgindo no Norte a Igreja Presbiteriana dos Estados Unidos da América (PCUSA ), que tendia para uma postura antiescravista, e no Sul a Igreja Presbiteriana dos Estados Unidos (PCUS), descrita como mais conservadora e defensora da permanência da escravidão (REILY, 2003, p. 128-140).

Todavia tal ruptura não inviabilizou os projetos missionários destas instituições que, pelo contrário, passaram a agenciar notáveis esforços como o envio de recursos financeiros e humanos para - Brasil e a América Latina a partir da segunda metade do século XIX, atuação estendida durante quase todo o século $X X^{8}$. Esforços estes agenciados tanto pela Igreja do Norte, por meio de sua Junta de Missões sediada em Nova York, como pela recém-estruturada (1861) Igreja Presbiteriana dos Estados Unidos (PCUS), cuja sede da sua organização missionária (Comitê de Missões Estrangeiras) localizava-se na cidade de Nashville, no estado do Tennessee.

Assim, terminada a Guerra de Secessão, estas instituições religiosas, por meio dos setores de missões, passaram a incentivar e enviar um número significativo de pastores e missionários para várias regiões do Brasil com o objetivo de atrair os brasileiros a professarem nova doutrina (REILY, 2003, p. 29).

Para o historiador francês Émile Léonard (2002), uma considerável leva de missionários cruzou o Oceano Atlântico em direção ao Brasil após a derrota dos Confederados. Ao mesmo tempo, o historiador afirma que não eram apenas estes missionários que migravam, mas que havia também outro movimento. Várias famílias protestantes do Sul dos EUA fizeram este mesmo caminho, sobretudo para a província de São Paulo (LÉONARD, 2002, p. 85). Seguindo este raciocínio, o Doutor em Teologia Duncan Reily afirmou ter sido este deslocamento, em grande medida, incentivado e reforçado por uma série de condições, assim que "atraídos pela boa terra a preços acessíveis, pelo clima e pela ajuda do governo imperial, além da possibilidade de adquirirem escravos no Brasil, o que não lhes era mais possível na sua terra de origem" (REILY, 2003, p. 129-130).

Todavia, no que tange à temática da escravidão, é importante salientar os reflexos no Brasil dos embates que permeavam setores da sociedade nos EUA em torno da permanência ou não do trabalho escravo. Profundamente inseridos nesse conflito, havia por parte dos missionários provenientes da

6 Convencionou-se classificar a presença do protestantismo no Brasil a partir de três categorizações: protestantismo de invasão, de imigração e de missão. A terceira categoria dessa presença religiosa foi denominada de protestantismo de missão, quando as diversas igrejas protestantes dos EUA, sobretudo a partir de meados do século XIX, passaram a enviar sistematicamente missionários ao Brasil com o objetivo bem definido de propagar a fé protestante e conquistar seguidores em uma nação essencialmente católica.

7 É importante informar ao leitor que em 1958 a Igreja Presbiteriana dos Estados Unidos da América (PCUSA) formalizou uma união com a Igreja Presbiteriana Unida acarretando na formação da Igreja Presbiteriana Unida dos Estados Unidos da América (UPCUSA) (NASCIMENTO, 2007, p. 69).

$8 \mathrm{~A}$ presença destas Missões (presbiterianas, batista, entre outras) norte-americanas no Brasil, assim como em várias partes da América Latina, África e Ásia, ainda carece de investigações consistentes no campo da História, da Antropologia e da Sociologia. 
Igreja Presbiteriana dos Estados Unidos da América uma tendência maior para condenar a escravidão ao contrário daqueles enviados pela Igreja Presbiteriana dos Estados Unidos, cuja postura inclinava-se muito mais para a tolerância ou defesa da escravidão. No Brasil, sinais desse confronto se fizeram presentes com o próprio Ashbel Green Simonton, enviado pela Igreja do Norte, que deixou registrado em seu diário de viagem várias passagens dando conta da sua posição antiescravista tanto em seu país como no Brasil (CÉSAR, 2009, p. 115-126).

Além dos aspectos até aqui delineados, considere-se ainda que em meados do século XIX os missionários protestantes agiam motivados por uma concepção política, social e religiosa bem demarcada em relação ao seu papel perante o mundo e, sobretudo, frente à América Latina. Provavelmente interagiam, como a maior parte dos seus contemporâneos, com uma autoimagem carregada de significados religiosos construída em torno da chegada dos puritanos ingleses nas Treze Colônias - imigrantes protestantes fugidos da perseguição religiosa do século XVII na Inglaterra. Essa percepção do povo norte-americano foi descrita por Reily da seguinte maneira:

Como Deus, por Moisés, libertou os israelitas da escravidão no Egito, pela travessia maravilhosa do Mar Vermelho, os puritanos se libertaram da opressão dos soberanos ingleses Tiago I e Carlos I, atravessando o Atlântico no pequeno navio Mayflower. Deus estabelecera seu pacto com o povo liberto, no Sinai; paralelamente, os puritanos, antes de pôr os pés em terra seca na América, firmaram o Mayflower Compact. Explicitaram que havia encetado sua viagem de colonização "para a glória de Deus, avanço da fé cristã e honra do nosso rei e país [...] solene e mutuamente, na presença de Deus, e cada um na presença dos demais, compactuamos e nos combinamos em um corpo político civil”. Finalmente, como Josué havia conquistado a terra da promissão, os americanos viam como seu "destino manifesto" conquistar o Continente de oceano a oceano, espalhando os benefícios de uma civilização republicana e protestante por toda a parte. Assim, os Americanos do Norte observavam, jubilosos, o início do processo da libertação da América Latina [...]. (REILY, 2003, p. 37).

Este imaginário religioso de civilização escolhida diante de pacto feito com Deus ainda durante a travessia para uma terra distante, ao norte da América - dentre outras construções, tendo por base todo um simbolismo religioso e moral - foi incorporado à sociedade norte-americana. Mentalidade essa extremamente utilizada em meados do século XIX para fundamentar o que ficou conhecido como $O$ Destino Manifesto, movimento que consolidou as bases teóricas (moral, cultural e ideológica) para a conquista de novos territórios e povos. Esse movimento foi a sistematização da crença na qual os anglo-saxões - ou seja, o povo branco norte-americano - autoafirmavam-se como raça superior ajudada por Deus e em que a religião protestante era o verdadeiro caminho rumo ao paraíso, o que lhes garantia o direito e a obrigação cristã de regenerar os povos atrasados (MENEZES, 2010, p. 19-20, 56).

A crença fortemente alicerçada em torno de um povo eleito - escolhido por Deus - interagia com o imaginário artístico norte-americano. É dessa maneira que entendemos uma série de caricaturas produzidas nos séculos XIX e XX, circulantes na imprensa, sobretudo em periódicos e revistas. 0 cientista político John Johnson, no livro Latin America in Caricature (1980), analisou - fazendo uso de ca- 
ricaturas - a mentalidade recorrente sobre o papel político que os EUA deveriam desempenhar para com seus vizinhos. Como mostrou Alberto Del Castillo, a produção de imagens interage participando de esquemas sociais em circulação em dado momento (CASTILLO, 2006, p. 32). Com base nessas considerações, ao analisar a imagem utilizada por Johnson podemos afirmar que ela não se encontra fora de um código cultural legitimado por importantes setores sociais norte-americanos, sobretudo protestantes. Ou seja, a imagem era representativa de linguagem visual carregada de sentidos e significados destinados aos leitores daqueles periódicos.

Figura 1 - Caricatura de William Allan Rogers

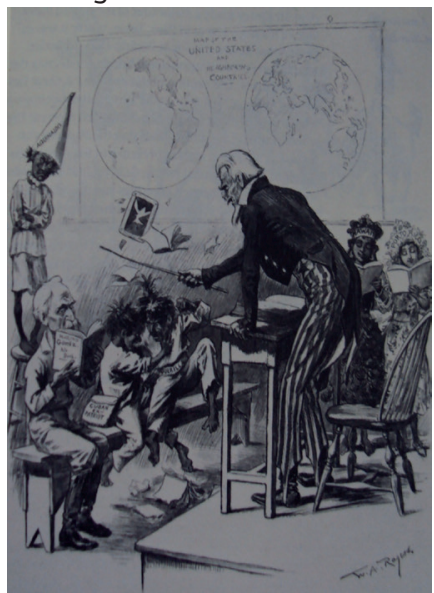

Fonte: Harper's Weekly, Nova York (1898 apud JOHNSON, 1980, p. 217).

William Rogers, um dos cartunistas do jornal Harper's Weekly, projetou seu olhar sobre a América Latina e o papel exercido pelos EUA na região. Em sua perspectiva, a nação protestante do Norte foi representada por um homem em posição elevada e vara na mão, de estatura imponente e bem-vestido, características bem marcantes na composição do imaginário popular da maioria dos norte-americanos. Figura a imagem de alguém que ensina/civiliza os povos da América Latina.

O fato já havia ocorrido antes a outros países, os quais foram representados por pessoas de aspectos mais adultos e comportamentos exemplares, além de bem-vestidas. Algumas nações são retratadas como infantis, rebeldes e carentes, encontradas descalças e mal-vestidas, e como toda criança devem ser educadas e civilizadas. 0 método empregado nesse processo, como bem sugere a imagem, era o disciplinamento constante e força. Não é, pois, por acaso que o caricaturista projetou os EUA, usando um chicote pronto para disciplinar os países considerados rebeldes da América Latina.

9 Harper's Weekly era uma publicação de política semanal da cidade de Nova York que circulou entre 1857 e 1916, também intitulado de $\mathbf{O}$ Jornal da Civilização. Apresentava notícias nacionais e internacionais, ficção, ensaios diversos e humor, ao lado de ilustrações. De ampla circulação nos Estados Unidos, tinha como importante característica a produção de ilustrações, ou seja, de charges políticas. Disponível em: http://en.wikipedia.org/wiki/Harper’s_Weekly. Acesso em: 31 maio 2013. 
Caricaturas semelhantes nas quais a América Latina e seus aspectos políticos, econômicos e sociais eram representados a partir de um código cultural e/ou uma concepção de mundo fortemente aceita eram bastante comuns em circulação nos jornais e revistas dos EUA em vários outros momentos (JOHNSON, 1980; PORFÍRIO, 2009). Os missionários norte-americanos não estavam fora desse código cultural. 0 teólogo e filósofo Rubem Alves afirmou sobre esses agentes que, ao chegarem ao Brasil, a partir de meados do século XIX, sempre se comportaram como os representantes de uma cultura tida como civilizada e superior em detrimento da cultura nacional e da religião católica aqui consolidada (ALVES, 2005; DUPAS, 2009).

É dentro desse complexo quadro que se insere George William Butler e suas ações como missionário e médico em Pernambuco.

\section{GEORGE WILLIAM BUTLER NO AGRESTE DE PERNAMBUCO}

Influenciado em grande medida pelo discurso segundo o qual os Estados Unidos deveriam ajudar a promover o progresso e a civilização das outras nações, George Butler chegou ao Brasil em 1883 com 30 anos de idade. Proveniente do estado da Geórgia, sul dos Estados Unidos, foi enviado ao Brasil pela Junta de Nashville (entidade missionária da Igreja Presbiteriana dos Estados Unidos/PCUS) juntamente com a sua esposa, a senhora Mary Rena Humprey Butler.

Entre os anos de 1883 e 1919 Butler exerceu as atividades de missionário e médico no Norte do Brasil ${ }^{10}$, primeiro no Maranhão, até 1892 e depois em Pernambuco, em momento de significativas transformações. Na política, a monarquia tornou-se pouco atraente para as elites dirigentes e agrárias, consolidando às pressas e sem a participação popular o sistema republicano em 1889. No mundo do trabalho o Brasil deixava, pelo menos oficialmente, de praticar o trabalho compulsório, mas sem efetivar a tão necessária integração política e social dos ex-escravos e sem modificar a estrutura fundiária a partir de reforma agrária.

$\mathrm{Na}$ historiografia brasileira que trata da disseminação do protestantismo encontramos algumas referências à atuação de Butler. Segundo Émile G. Léonard, o referido missionário aproximou-se das classes mais influentes da política e da economia na cidade de São Luís, a exemplo de membros da Junta Governativa implantada com o surgimento da República (LÉONARD, 1981, p. 97-98).

Ainda durante o Império, em 1887, foi capaz de construir em São Luís a primeira igreja presbiteriana, desconsiderando a Constituição imperial de 1824 que previa em seu Artigo $5^{\circ}$ que "a religião Católica Apostólica Romana continuará a ser a do Império”. A construção de templos era terminantemente vedada aos estrangeiros de outras correntes cristãs. A quebra dessa ordem poderá indicar já certa fragilidade por parte do Império e uma notável influência de Butler entre as elites dominantes do Maranhão.

10 Naquele momento a região Norte abrangia tanto as áreas chuvosas como os estados com baixos índices pluviométricos. Apenas a partir de 1969 foi criada a região Nordeste, invenção importante para consolidar uma representação social, política e econômica das áreas pouco chuvosas. 
Entre 1893 e 1919, com o Brasil já consolidado como república, Butler concentrou seus esforços como missionário e médico em Pernambuco. Em Recife, foi responsável pela edificação, também, do primeiro templo presbiteriano, localizado na praça Joaquim Nabuco. Posteriormente, em 1894, deslocou-se para Garanhuns e, em seguida, para Canhotinho, cidades beneficiadas pelas estações da linha férrea da Great Western que partia do Porto do Recife (UM MÉDICO..., 2015). Em Canhotinho construiu, além de um templo, uma escola e um hospital.

É importante salientar que a construção da igreja em Canhotinho não contou com recursos financeiros da Igreja Presbiteriana dos Estados Unidos/PCUS, mas da venda de orquídeas exportadas do Brasil para Nova lorque e negociadas por conhecidos de Butler (VERAS, 2015, p.169-190). Em relação à construção do hospital, de acordo com relatos presentes no livro de Henry F. Williams, publicado em 1917 com o título In Brasil: the brazil missions of the Presbyterian Church in the United States"11, apresenta-se como um grande feito de Butler, o que foi possível graças ao envio de considerável quantia (cinco mil dólares) doada por um amigo metodista que residia nos Estados Unidos. Não por acaso Butler nomeou o local por Enoch's Hospital, uma forma de homenagear o doador.

Em visita à cidade de Canhotinho não localizamos em seus arquivos iconografias do referido hospital. A imagem que dispomos encontra-se publicada no livro de Henry Williams. A partir dessa imagem objetivamos problematizar alguns aspectos da atuação de Butler naquela cidade. Pelo que já foi mencionado e com o que a imagem abaixo parece corroborar, suas ações não estavam pautadas diretamente pelas determinações da Junta de Nashville, nem mesmo dependia financeiramente da Igreja Presbiteriana dos Estados Unidos para efetivar os projetos julgados necessários para o bom desempenho do seu trabalho como missionário e médico.

Figura 2 - A imagem encontra-se publicada no livro de Henry Williams

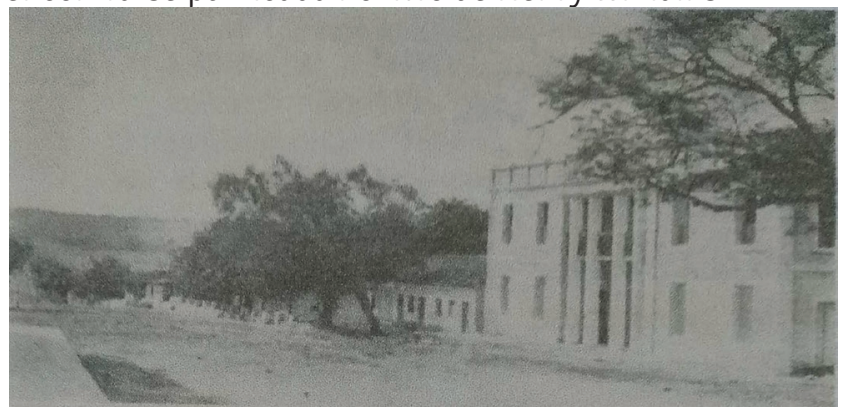

Fonte (WILLIAMS, 1917)

O fotógrafo projeta parte da cidade de Canhotinho do início do século XX, dando visibilidade a um conjunto de casas de dimensões e formatos bastante modestos quando comparadas ao Enoch's Hospital, construído em estilo neo-clássico. Chama a atenção a diferença arquitetônica entre o hospital e

11 Este livro foi publicado pela Presbyterian Church in the United States (PCUS). São relatos descrevendo os avanços do trabalho missionário no Brasil. 
as demais construções. É preciso considerar os códigos culturais em circulação na imagem, aspectos visuais que emitem uma série de outros significados sociais.

Em época em que o estado brasileiro se fez bastante ausente, ainda mais em cidades distantes da capital, tamanho empreendimento fazia de George Butler alguém visível aos olhos da maioria da população assim como para as autoridades políticas daquele município. Em um país que até recentemente mantinha o catolicismo como religião de Estado, o protestantismo, assim como outras correntes religiosas, era visto como algo fora de lugar, um out side. Ser um "crente", como era denominado todo aquele que frequentava igrejas não católicas, muitas vezes causava indignação e em alguns momentos até atos de violência em parte dos católicos.

A construção do Enoch's Hospital fez de Butler um aceito, ou pelo menos foi um redutor da grande repulsa comumente sofrida por aqueles que se diziam protestantes, sobretudo entre os missionários estrangeiros. Isso é possível constatar-se no livro/relatório de Henry Williams, de 1917. Os números presentes no relatório indicam que a igreja presbiteriana em Canhotinho contava com 300 fiéis, e 0 movimento no hospital, até aquele momento, ultrapassava 8.500 atendimentos. Dados considerados bastante significativos pelo relatório.

Em outra imagem, também publicada no livro In Brasil: the brazil missions of the Presbyterian Church in the United States, evidencia-se como Butler estabeleceu relações estratégicas capazes de garantir a sua sobrevivência como missionário protestante em um país essencialmente católico ${ }^{12}$.

Figura 3 - Essa imagem também foi publicada em livro sobre George Butler, encomendada por entidade da Igreja Presbiteriana dos Estados Unidos/PCUS

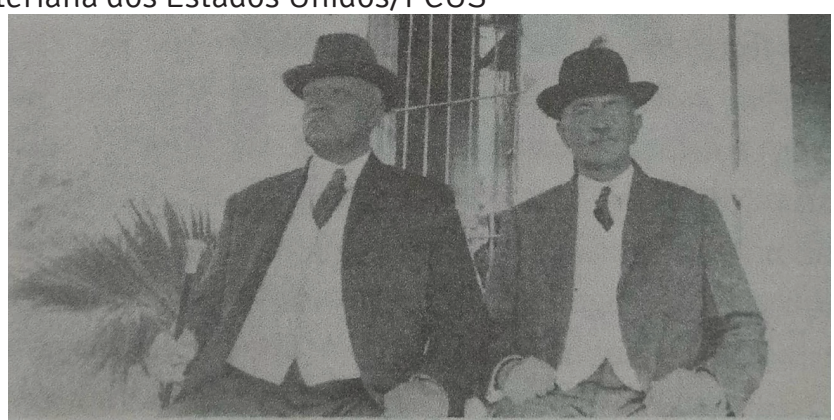

Fonte: (FERREIRA, 2007).

Assim como na passagem pelo Maranhão, na cidade de Canhotinho, Butler também estabeleceu semelhantes relações, muito provavelmente com a principal autoridade municipal à época, o coronel Caetano Vidal dos Santos. Para melhor descrever o que seria um coronel naquele momento, recorro à crônica Linhas Tortas do escritor alagoano Graciliano Ramos, um contemporâneo de Butler, publicada inicialmente no Jornal de Alagoas, em março de 1915. Diz a crônica em determinado fragmento:

12 Essa imagem também foi publicada em livro sobre George Butler, encomendada por entidade da Igreja Presbiteriana dos Estados Unidos/PCUS, responsável pelas atividades missionárias no Norte e Nordeste do Brasil (FERREIRA, 2007). 
Mandatários do governo, forjadores de eleições, mais ou menos coronéis, caciques em miniatura, têm frequentemente, para infundir respeito, uma espada da Guarda Nacional [...]. Possuem um factótum, pau para toda obra, secretário particular e muitas coisas mais [...]. (RAMOS, 2002, p. 6).

Ainda em sintonia e em certa medida parafraseando outros fragmentos desta crônica, podemos afirmar que:

A Constituição do Brasil tem um buraco. Observa que além dos três poderes integrantes do sistema republicano - executivo, legislativo e judiciário - existe um quarto poder: poder que considera vago, impreciso e que apresenta-se como o sumário dos três já mencionados. Em seu comando não há um ministro de estado - figura comum no Brasil desde o período imperial e cuja função é auxiliar diretamente na administração de uma nação - temos, isto sim, a figura de inúmeros chefes políticos, 'funcionários de atribuições indeterminadas, mas ilimitadas' que, para o autor, são as verdadeiras forças políticas atuantes no país, 'o resto é lorota'. (VILELA, 2014, p. 23-24).

O médico-missionário George Butler possivelmente não estava interessado na política partidária comandada pelo coronel Caetano Vidal durante a chamada República Velha, mas essa relação com o chefe político local the proporcionava uma série de outros benefícios, como a proteção e o respeito de todos na cidade de Canhotinho e demais municípios circunvizinhos. Butler conhecia muito bem a prática da violência e os riscos inerentes a sua atividade como missionário. Ele tinha sido vítima de um atentado na cidade de São Bento do Una, ocasião em que seu amigo e companheiro de evangelização, Manuel Vilela, mais conhecido como Né Vilela, foi assassinado.

\section{A CONSTRUÇÃO DE UMA TRAJETÓRIA: A MORTE DE GEORGE WILLIAM BUTLER}

No ano de 1918 Butler retornou aos Estados Unidos com sua família (esposa e seis filhos), deixando um dos filhos, o médico Humphrey, como responsável pelo hospital em Canhotinho. O objetivo da viagem era descansar e resolver questões referentes aos estudos das crianças (FERREIRA, 2007, p. 109), mas durante sua passagem contribuiu como médico da Cruz Vermelha no combate à gripe espanhola que atingiu os EUA e boa parte da América, contraindo, nesse período, a enfermidade à qual se dedicava a combater. E mesmo com a saúde comprometida retornou ao Brasil em abril de 1919, logo após o final das supostas férias, dessa feita sem a esposa, dona Rena, e os filhos.

Aqui, de acordo com Ferreira, retomou suas atividades missionárias de maneira intensa uma vez que desejava expandir a presença do presbiterianismo em outras localidades próximas a Canhotinho e na região Norte, mais precisamente no Pará. É possível que os esforços empreendidos com a viagem de retorno ao Brasil e o seu empenho com as atividades de expansão do protestantismo hajam contribuído na po- 
tencialização de sua debilidade física ${ }^{13}$, pois no dia 27 de maio de 1919, aos 65 anos de idade, faleceu 0 médico, o missionário, o amigo; para outros um inimigo do catolicismo, alguém a ser evitado, repudiado.

A morte de Butler foi anunciada pelo Jornal do Commercio no dia 11 de julho, sendo apresentada como causa uma congestão hepática. A notícia faz menção a um homem capaz de construir significativa base social em Canhotinho, pois "o comércio, em sinal de sentimento, cerrou suas portas até a hora do enterro". A despeito disso podemos afirmar que essa inserção e aceitação não foi um processo linear e homogêneo, havendo sido, aliás, desde a sua chegada ao Brasil em 1883, atingido em vários momentos e de diversas maneiras por certo discurso de ódio religioso praticado por setores da Igreja Católica Apostólica Romana (FERREIRA, 2007).

Um dos momentos mais graves de intolerância religiosa na trajetória de George Butler e dos que com ele estavam na propagação do protestantismo foi no caso do assassinato de Manuel Corrêa Vilela, o Né Vilela, em 7 de fevereiro de 1898, na vila de São Bento ${ }^{14}$.

Sobre o episódio da morte de Né Vilela recorro às lembranças da minha infância, em Águas Belas, quando em vários momentos escutei relatos que o apresentavam como um parente ilustre do passado, quase um mártir. Imagem reforçada por livros que tiveram grande circulação no meio protestante, como A Bíblia e o bisturi, do pastor presbiteriano Edijéce Martins Ferreira, que escreveu com o objetivo narrar os grandes feitos de George Butler desde a sua chegada ao Brasil, em 1883, até a sua morte, em 1919.

Butler é apresentado, vivenciando situações limites, perigosas e inusitadas, mas sempre conseguindo vencer todos os seus supostos inimigos. E dentre os inúmeros episódios estruturados para esta finalidade encontramos a narrativa sobre a atuação de Né Vilela no momento do seu próprio assassinato, sendo descrito como um amigo de Butler e propagador do protestantismo em Canhotinho e no seu entorno ${ }^{15}$. Mesmo descrevendo Né Vilela como um herói, cujo fim é trágico, o personagem central de seu enredo é de fato Butler e sua capacidade de superação.

De acordo com o Processo Crime $\mathrm{n}^{0} 32^{16}$, João Ribeiro da Silva, um estafeta (correio a cavalo), sabendo da presença de um grupo de protestantes provenientes da cidade de Canhotinho, teria sido encorajado por terceiros e pela embriaguez a praticar aquele crime. 0 resultado proveniente do enfrentamento provocado por Negro Velho, como era conhecido João Ribeiro, foi a morte de Né Vilela, que foi atingido por uma faca ou punhal. Negro Velho foi preso e condenado a vinte e dois anos e três meses de prisão. Seu advogado recorreu da sentença ao Tribunal de Justiça e em segundo julgamento

13 Não temos informações precisas sobre o real motivo da sua morte. É difícil imaginar que Butler, sabendo da gravidade e dos riscos provenientes da gripe espanhola, deixasse os EUA (a viagem de navio durava vários dias) sem que sua saúde estivesse de fato reestabelecida.

14 São Bento do Una é uma cidade localizada no agreste de Pernambuco, distante da capital, Recife, aproximadamente $215 \mathrm{~km}$. 15 Entendemos que essa imagem de mártir, de herói do protestantismo, simplifica ao extremo as trajetórias desses personagens. Tais adjetivações e enquadramentos não são capazes de problematizar o que foi aquele momento histórico. É preciso dar conta da complexidade que envolveu a violência praticada por setores da Igreja Católica Romana, ou seja, uma poderosa estrutura que não pretendia perder parte da sua hegemonia no campo religioso. É necessário, portanto, compreender o assassinato de Manuel Vilela dentro dessa engrenagem de poder.

16 Arquivo pessoal do autor. 
sua pena foi reduzida a dezessete anos e seis meses, e por fim um terceiro julgamento aconteceu em 15 de julho de 1902 quando Negro Velho foi absolvido do crime.

Em análise rápida do processo - o nosso objetivo não foi investigar a morte de Manuel Corrêa Vilela, mas fragmentos da trajetória de George Butler - não identificamos com precisão elementos comprobatórios de que o alvo principal de João Ribeiro fosse mesmo o "gringo", conforme propagado na memória coletiva e individual e em vários escritos memorialísticos: essa seletividade em torno do missionário/ médico é uma construção que deve ser repensada e problematizada pelos historiadores profissionais.

Entretanto o processo evidencia que naquele momento ser protestante e/ou propagar a nova fé poderia ser bastante perigoso assim como o foi para Manuel Vilela, George Butler e tantos outros; de igual modo o processo também evidencia que a nossa justiça foi e continua sendo palco de uma série de injustiças e seletividades. Seria, aliás, muito importante - embora não saibamos se possível - investigar a maneira como Butler reagiu a essa decisão da justiça e se ele fez referências em cartas e relatórios para a sua Missão no EUA.

Entendemos que o centenário da morte de George William Butler possa provocar novos e profundos estudos capazes de suscitar questões que, de fato, contribuam para a construção da sua trajetória como missionário e médico. Mas uma trajetória que precisa estar em sintonia com um modelo de civilização norte-americano com o qual Butler comungava e desempenhava. Estar em relação com as disputas de poder que envolveu, e ainda envolve, setores protestantes - e mais recentemente evangélicos - com a Igreja Católica Apostólica Romana. É nessa encruzilhada que vamos encontrar a riqueza de uma vida, grandeza que a pura e simples adjetivação e qualificação de um personagem são incapazes de projetar.

\section{REFERÊNCIAS}

ALVES, Rubem. Religião e repressão. São Paulo: Loyola, 2005.

ARNOLD, Frank L. Uma longa jornada missionária. São Paulo: Cultura Cristã, 2012.

AZEVEDO, Cecília. Em nome da América: os corpos da paz no Brasil. São Paulo: Alameda, 2007.

BANDEIRA, Luiz Alberto Moniz. Presença dos Estados Unidos no Brasil (Dois séculos de história). Rio de Janeiro: Editora Civilização Brasileira, 1978.

BLACK, Jan Knippers. A penetração dos Estados Unidos no Brasil. Recife: Fundação Joaquim Nabuco, Editora Massangana, 2009.

CASTILLO TRONCOSO, Alberto del. Conceptos, imágenes y representaciones de la niñez em la ciudad de México, 1880 - 1920. México - DF.: El Colégio de México, Centro de Estudios Históricos; Institutos de Investigaciones Dr. José María Luis Mora, 2006.

Interfaces Científicas • Aracaju • V.9 • N.2 • p. 468 - 483 • 2021 - Fluxo Contínuo 
CÉSAR, Elben M. Lenz. Mochila nas costas e diário na mão: a fascinante história de Ashbel Green Simonton. Viçosa, MG: Ultimato, 2009.

COSTA, Priscila Borba. O Destino Manifesto do povo estadunidense: uma análise dos elementos delineadores do sentimento religioso voltado à expansão territorial. Congresso Internacional de História, 5, 2011, Maringá. Anais[...], Maringá: UEM, 2011.

DUPAS, Gilberto. Religião e sociedade. In: SILVA, Carlos Eduardo Lins da (org.). Uma nação com alma de igreja: religiosidade e políticas públicas nos Estados Unidos. São Paulo: Paz e Terra, 2009.

FERREIRA, Edijéce M. A Bíblia e o bisturi. São Paulo: Cultura Cristã, 2007.

FORSYTH, William B. Jornada no Império: vida e obra do Dr. Kalley no Brasil. São Paulo: Fiel, 2006.

GIESBRECH, Érica. Fiéis em fuga? A nova configuração da Igreja Presbiteriana do Brasil.

Dissertação (Mestrado em Antropologia) -Universidade Estadual de Campinas, Campinas, SP, 2002.

JOHNSON, John J. Latin America in caricature. Austin: University of Texas Press, 1980.

LÉONARD, Émile G. 0 protestantismo brasileiro: estudo de eclesiologia e história social. São Paulo: ASTE, 2002.

MANUAL Presbiteriano. São Paulo: Editora Cultura Cristã, 1997.

MARTINO, Luís Mauro Sá (org.). Sociologia da religião e mudança social: católicos, protestantes e novos movimentos religiosos no Brasil. São Paulo: Paulus, 2004.

MATOS, Alderi Souza de. Os pioneiros presbiterianos do Brasil 1859-1900: missionários, pastores e leigos do século 19. São Paulo: Cultura Cristã, 2004.

MENDONÇA, Antonio Gouvêa. 0 celeste porvir: a inserção do protestantismo no Brasil. 3.ed. São Paulo: EDUSP, 2008.

MENDONÇA, Antonio Gouvêa. Protestantismo brasileiro, uma breve interpretação histórica. In: SOUZA, Beatriz Muniz; MARTINO, Luís Mauro Sá (org.). Sociologia da religião e mudança social: católicos, protestantes e novos movimentos religiosos no Brasil. São Paulo: Paulus, 2004.

MENEZES, Alfredo da Mota. Ingênuos, pobres e católicos: a relação do EUA com a América Latina. Rio de Janeiro: Fundo de Cultura, 2010. 
MESQUIDA, Peri. Educação protestante e processo civilizador na América Latina: de facundo ao solitário. Simpósio Internacional Processo Civilizador, 10, 2007, Campinas. Anais[...], Campinas: UNICAMP, 2007.

NASCIMENTO, Ester Fraga Vilas-Bôas Carvalho. Educar, curar, salvar: uma ilha de civilização no Brasil tropical. Maceió: EDUFAL, 2007.

PEREIRA, Rodrigo Nóbrega Moura. A nação brasileira e o protestantismo: religião e americanismo no projeto nacional de Tavares Bastos. Revista Intellectus, Rio de Janeiro, ano 06, v. II, 2007.

PORFÍRIO, Pablo F. de A. Medo, comunismo e revolução: Pernambuco (1959-1964). Recife: Ed. Universitária da UFPE, 2009.

RAMOS, Graciliano. Linhas tortas: obra póstuma. Rio de Janeiro: Recorde, 2002. p. 6.

REILY, Alexander Duncan. História documental do protestantismo no Brasil. São Paulo: ASTE, 2003.

SOUZA, José Roberto. Mapeamento histórico do(s) protestantismo(s) em terra brasilis: o protestantismo de missão e a contribuição de Ashbel Green Simonton. Revista Paralellus, Recife, ano 2, n. 4, p. 137-155, 2011.

UM MÉDICO, um missionário, um abnegado, um “digno de ser lembrado”: a memória e o esquecimento nas biografias de George William Butler. Simpósio Nacional de História - Lugares dos historiadores: velhos e novos desafios, 28, 27 a 31 de julho de 2015. Anais[...], Florianópolis, SC, 2015. Disponível em: http://www.snh2015.anpuh.org/resources/anais/39/1439816498_ARQUIVO_ TEXTOANPUH-2015.pdf. Acesso em: 20 de jul. 2017

VERAS, Rogério de Carvalho. 0 missionário e o coronel: uma iconografia do médico-missionário George Butler. Revista Ambivalências, v. 3, n.6, p. 169-190, jul./dez. 2015

VILELA, Márcio Ananias Ferreira. A trajetória política de Francisco Heráclio do Rêgo. Recife: Ed. Universitária da UFPE, 2014.

VILELA, Márcio Ananias Ferreira. Discursos e práticas da Igreja Presbiteriana do Brasil durante as décadas de 1960 e 1970: diálogos entre religião e política. Recife: Ed. UFPE, 2015.

WILLIAMS, Henry F. Brasil: the Brazil missions of the Presbyterian Church in the United States. Presbyterian Church in the United States (PCUS). 1917. 


\section{(2) (1) (-)}

Este artigo é licenciado na modalidade acesso abertosob a Atribuição-Compartilhalgual CC BY-SA 